\title{
ACHOLURIC JAUNDICE IN A NEWBORN INFANT
}

BY

\author{
DUNCAN MACAULAY \\ From the City Hospital, Derby
}

(Received for Publication June 28, 1950)

Congenital familial haemolytic anaemia in newborn infants has come to be regarded almost as synonymous with erythroblastosis foetalis in one of its varieties. The following case is reported as a reminder that the picture of an acute haemolytic anaemia in early life can be due to other causes.

\section{Case Report}

Mrs. C., the mother, of the affected infant, came under observation for the first time in 1940, with a history of chronic backache, puffiness of the eyes, and frequency of micturition. These symptoms were discovered to be due to pyelitis which was treated with sulphonamide, with marked improvement. At this time she was noticed to be slightly jaundiced and her spleen was enlarged to three fingers' breadth below the costal margin. A routine blood count showed haemoglobin $45 \%$, red blood cells $3,060,000$, colour index $0 \cdot 73$. The red cells were said to be normal in size and shape in stained films. She was discharged home after four weeks in hospital with instructions to take iron at home.

Her first child was born in 1941. The notes of this delivery were unfortunately lost owing to the war-time dislocation of the hospital's routine. The infant was apparently normal but the mother received several transfusions in the lying-in period.

The second pregnancy in 1943 was complicated by toxaemia with oedema and albuminuria. She was admitted for treatment and was found to be grossly anaemic, her haemoglobin being $23 \%$. She was again transfused and went into premature labour which resulted in the birth of a male infant weighing $4 \mathrm{lb} .15 \mathrm{oz}$. This infant progressed satisfactorily until the sixteenth day when he was noted to be very pale; the infant died suddenly on the following day. Post-mortem examination revealed the cause of death to have been bronchopneumonia complicating haemolytic anaemia which was attributed to erythroblastosis foetalis.

After this confinement the mother's blood was fully investigated and she was found to have typical acholuric jaundice. Her red cells showed definite spherocytosis (mean corpuscular average thickness $3 \cdot 7 \mu$ ). Fragility tests in saline solutions showed haemolysis beginning at $0.65 \%$ and almost complete at $0.45 \%$. Early in 1944 her spleen was removed and microscopic examination was said to show a 'structure typical of acholuric jaundice '.

The third pregnancy terminated in 1948 in the birth of a normal full-term male infant. Repeated blood investigations on this infant (including fragility tests) failed to reveal any evidence of a blood dyscrasia.

The fourth pregnancy also went to term and resulted in the birth of a mature female infant. The mother's Wassermann reaction was negative in this as in the other pregnancies. This child was carefully watched and the following blood values were obtained:

Cord blood at birth. Hb. $15 \cdot 6$ g.\%. R.B.C. 4,190,000. On the second day. Hb. $23 \cdot 7$ g.\%. R.B.C. 6,320,000. On the fourth day. Hb. $23 \cdot 4$ g.\% $\%$ R.B.C. 7,450,000. On the seventh day. Hb. $17 \cdot 1$ g. $\%$. R.B.C. $5,050,000$. On the tenth day. Hb. $18 \cdot 3$ g.\%. R.B.C. 6,980,000.

Fragility tests on the sixth day gave results almost identical with the mother's, haemolysis beginning at $0.65 \%$ and being practically complete at $0.45 \%$. Fragility tests on the mother's erythrocytes showed the persistence of increased fragility; haemolysis began at $0.6 \%$ saline and was almost complete at $0.45 \%$. The infant appeared perfectly normal on the fourteenth day in spite of the undoubted evidence of abnormality of the erythrocytes and was discharged with the mother. Three days later, however, she was seen again, and on this occasion the findings were Hb. 7.1g. \%; R.B.C. $1,890,000$; mean cell diameter $5 \cdot 7 \mu$; mean corpuscular average thickness $3 \cdot 1 \mu$; reticulocytes $5 \%$. The infant was pale but not appreciably jaundiced and the spleen was just palpable. A transfusion of whole blood was given and the child discharged. She was readmitted on the thirty-seventh day of life, having had a further haemolysis. The findings were Hb. 9.9 g. \%; R.B.C. $2,950,000$. The baby was pale but again not perceptibly jaundiced. A further transfusion was given and she was discharged. Since then she has been seen repeatedly for a period of four months and no further haemolytic episodes have occurred.

Mrs. C.'s relatives were investigated at the time the diagnosis was established in 1943, and no other affected members of her family were discovered. Her serological groups are given by the Regional Transfusion Laboratories as Group $\mathbf{O}, \mathbf{R h}$ positive. The Regional Transfusion Officer comments:

- Mrs. C. was first referred to us during her 1947 pregnancy and later in her 1950 pregnancy. At no time have we been able to demonstrate immune antibodies in her serum nor have the infants shown any signs of immunization in that the direct Coombs tests have always been negative. Mrs. C.'s red cells contain the 
antigen $\mathrm{D}^{\mathrm{u}}$ and her children have been $\mathrm{D}$ positive. Since $D^{u}$ is a variant of $D$, no immunization occurs.

The two surviving children of the previous pregnancies have been reinvestigated since the birth of the fourth child and their blood has been found to be normal in all respects.

There is no doubt that this infant is a case of familial haemolytic anaemia or acholuric jaundice. The diagnosis rests on (1) the strong family history, (2) the occurrence of considerable blood destruction within a very short period, (3) the characteristic increase in fragility of the child's erythrocytes and the spherocytosis, (4) the exclusion of other causes of haemolysis at this age.

\section{Discussion}

Acholuric jaundice is recognized to be due to an inherited defect of the erythron, which is demonstrated by the abnormal erythropoiesis seen in bone marrow smears, by the abnormal contour of the erythrocytes in the circulating blood, by their excessive fragility in saline solutions, and by their liability to rapid destruction in the body. It is known that these characteristics persist in spite of clinical cure of the disease by splenectomy, and the examination of near relatives of frank cases has often revealed similar abnormalities in spite of the absence of symptoms. It is remarkable, however, how rarely this abnormality manifests itself in infancy. There is considerable variety of opinion about the frequency of clinical manifestations in early life. The following opinions have been encountered in standard text-books.

- Cases have been recorded in the first few hours of life. . . . The youngest recognized case in the author's series was 14 days old.' (Vaughan, 1936.)

'[Symptoms] may appear at birth or shortly afterwards.' (Wintrobe, 1942.)

- Jaundice, which is the most striking feature, may start at birth, or very soon afterwards: it is rarely delayed till after infancy.' (Gregory, 1933.)

- The disease may manifest itself any time between infancy and adolescence.' (Sanford, 1948.)

'The active form of the disease often does not manifest itself in infancy, but it may be present even at birth or may develop at any time.' (Josephs, 1940.)

- It can be observed in earliest childhood though definite symptoms appear usually at the beginning of the school age or shortly before.' (Opitz, 1935.)

'The disease seldom becomes apparent in infancy.' (Cooley, 1949.)

- Clinical manifestations are relatively rare in infants.' (Diamond, 1950.)

'Symptoms may appear at any age but are rare in infancy.' (Whitby and Newns, 1949.)

'The resulting haemolytic anaemia becomes manifest in early life but rarely in infancy.' (Kugelmass, 1941.)
There is little indication in most of these assertions of the occurrence of the disease in the neonatal period. The term 'infancy' so frequently used has no specific connotation. It may refer to the first year, or to the first two years of life.

Of reported cases of the active disease at or shortly after birth there is not a large number. Gripwall (1938) reported 31 cases in detail. Of these three were said to have had jaundice from birth but they were not seen until the ages of 10 years, 17 years, and 23 years, and none of them was apparently sufficiently ill in the early years of life to require medical care. Thompson (1939) records 43 cases from a special clinic. From his tables it appears that the youngest case was a child of 8 months, who was said to have been jaundiced for six months. Debré, Lamy, Sée, and Schrameck (1938), record 20 cases observed in a period of 12 years in Paris. The youngest was 4 months old at the time of discovery. Dawson (1931) in his Hume lectures on haemolytic icterus gives a genealogical table of an affected family in which four of the children were said to have been born jaundiced. No further details of these are given and the earliest onset of symptoms recorded in his case reports is at 2 years of age. Parsons (1938) in an extensive review of 'The Haemolytic Anaemias of Childhood' devotes only a small space to acholuric jaundice. He records two cases (in cousins) in whom symptoms began before the third and fourth months. Newns (1950) has collected 22 cases from the records of The Hospital for Sick Children, Great Ormond Street. Of these nine certainly, and one probably, exhibited symptoms before the age of 1 year, and in three others the diagnosis was established by the age of 1 year. Three of these cases were seen in the first month of life-one at one week, one at 10 days, and the third at one month. In four others symptoms were reported shortly after birth but the children were not seen until some time later. Fallon (1943) records seven cases of whom five were said to have had symptoms in early infancy. One was anaemic, with a reticulocytosis of $11 \%$ at 2 months; a second became jaundiced at two months and at 4 months had marked anaemia with reticulocytosis; the third was definitely anaemic at the age of $3 \frac{1}{2}$ months; the fourth case was said to have had attacks of jaundice since birth but did not come under observation until the age of 14 years; her fifth case is a curious one. The infant became jaundiced and anaemic at the age of 12 days and splenectomy was performed at the age of 2 months. There is no record of fragility tests and neither the clinical condition nor the blood values were improved by the operation. Meulengracht (1938) states that, - As far as I know, no case has ever been observed 
in which this effect [rise in haemoglobin content and erythrocyte count] failed to appear; nor has there been recorded any such case where there was a relapse of the anaemia subsequent to splenectomy.' There must therefore be considerable doubt about the accuracy of the diagnosis in this case of Fallon's. Diamond (1937) reported six cases of which the youngest was an infant of $4 \frac{1}{2}$ months whose symptoms began at the age of $2 \frac{1}{2}$ months. Josephs (1938) reported four cases in only one of which did the symptoms begin shortly after birth and he comments: "This is one of the few cases in which the evidence is fairly convincing that the disease was present at birth." Abt (1940) gave an account of three cases in two of whom the disease started at $4 \frac{1}{2}$ months; in the third case pallor and jaundice had been noticed from birth.

Detailed histories of cases showing evidence of the disease in the first month of life are recorded by Josephs (1938) (one case), Abt (1940) (one case), Conrad and Schmidt (1946) (one case), Schiff (1938) (one case), Hawksley (1934) (one case), Fallon (1943) (one case-diagnosis doubtful), and Newns (1950) (three cases). Of these Hawksley's is the most similar to the present one. The infant was the third affected child of its parents (two brothers had had their spleens removed because of acholuric jaundice): the infant appeared normal at birth: increased fragility and microcytosis were demonstrated on the second day of life; pallor was marked on the thirty-seventh day and the spleen was just palpable at the age of 7 weeks. In this case, as in the present one, the diagnosis was made before the onset of symptoms.

The present case appears to be the first in which the disease manifested itself in more than one member of the second affected generation in early infancy. It seems to be rare to obtain a positive family history when the disease appears in early infancy. Abt, writing in 1940 , stated that 'the occurrence of this condition in cousins, mentioned by Parsons, is the only instance in which a familial history has been noted when the disease occurred in early infancy. This is not quite correct, since Hawksley reported his case in 1934, but it may be taken as indicating the rarity of the appearance of the disease in the infants of affected families.

As regards symptomatology, David and Minot (1944) write that 'in the infant icterus is usually slight-pallor and splenomegaly being the most outstanding physical findings:. This is supported by Abt (1940) who says, 'When the illness is first manifested in early infancy, jaundice may be entirely absent, even though there is indisputable evidence of considerable increase in destruction of blood.' In the cases of Hawksley, Schiff, Conrad, and
Schmidt, and in two of Newns' cases pallor is recorded as the dominant symptom. This casts some doubt on the cases, such as those of Gripwall and of Dawson, in whom there was only a history of persistent jaundice after birth. Neonatal jaundice may be marked and persistent without any evidence of undue haemolysis. Still (1924) mentions an infant in whom it persisted for $9 \frac{1}{2}$ weeks.

The youngest infant submitted to splenectomy appears to be the case of Fallon's in whom it was performed at the age of 2 months. The operation was not successful, in that the condition was not relieved. Newns (1950) notes a case in which splenectomy was carried out at $2 \frac{1}{2}$ months. The infant survived the operation but died of bronchopneumonia and suprarenal haemorrhage at the age of $3 \frac{1}{2}$ months. The earliest successful operation is that recorded by Conrad and Schmidt (1946) at the age of 10 weeks. Diamond (1937) and David and Minot (1944) report successful operations at the ages of $4 \frac{1}{2}$ and 5 months. Abt (1940) advocates early splenectomy, and Fallon (1943) considers that if oparation is delayed recovery may be incomplete.

In spite of assertions to the contrary, it would appear that the occurrence of clinically significant haemolysis in infants born with the inherited abnormality of the erythron which is the characteristic feature of acholuric jaundice is a rare event. The present case appears to be the first recorded in which the disease, directly transmitted from an affected parent, has given rise to severe haemolytic anaemia in the neonatal period in more than one child.

\section{Summary}

A case is reported in which the inheritance of acholuric jaundice is demonstrated from mother to child in two of four children of an affected woman.

In both infants the disease became clinically apparent in the neonatal period.

This sequence of events is rare, if not unique.

I am indebted to Dr. D. V. Hubble, under whose care the infant was, not only for permission to publish, but for suggesting that this report be made. The numerous haematological investigations were carried out in the laboratory of the hospital under the supervision of Dr. G. R. Osborn. Dr. R. H. Malone, Regional Transfusion Officer to the Sheffield Hospital Region, provided the serological report. I am grateful to Dr. G. H. Newns for allowing me to see his material. This will be published at a later date.

\section{REFERENCES}

Abt, A. F. (1940). Amer. J. Dis. Child., 60, 812.

Conrad, E., and Schmidt, R. E. (1946). Ibid., 72, 731.

Cooley, T. B. (1949). In Brennemann, Practice of Pediatrics'. vol. 3 , ch. 16, p. 38. Hagerstown, Maryland.

David, J. K., and Minot, A. S. (1944). Amer. J. Dis. Child., 68, 327. 
Dawson of Penn, Lord (1931). Brit. med. J., 1, 921.

Debré, R., Lamy, M., Sée, G., and Schrameck, G. (1938). Amer. J. Dis. Chi'd., 56, 1189.

Diamond, L. K. (1937). Med. Clin. N. Amer., 21, 401. (1950). In Mitchell-Nelson, Textbook of Pediatrics,' 5th ed., p. 1110. Philadelphia.

Fallon, M. (1943). J. Pediat., 23, 721.

Gregory, H. H. C. (1933). In Parsons and Barling, 'Diseases of Infancy and Childhood,' vol. 1, p. 852. London.

Gripwall, E. (1938). Acka med. scand., Suppl. 96.

Hawksley, J. C. (1934). Proc. roy. Soc. Med., $27,942$.

Josephs, H. W. (1938). Bull. Johns Hopk. Hosp., 62, 25. (1940). In Holt and McIntosh, "Diseases of Infancy and Childhood,' 11 th ed., p. 629. New York.

Kugelmass, I. N. (1941). ' 'Blood Disorders in Children,' p. 258. London.

Meulengracht, E. (1938). In ' Handbook of Hematology,' ed. Downey, H., vol. 3, p. 2281. New York.
Newns, G. H. (1950). Personal communication.

Opitz, H. (1935). In Pfaundler and Schlossmann, 'The Diseases of Children,' ed. Peterman, vol. 2, p. 201. Philadelphia.

Parsons, L. G. (1938). Lancet, 2, 1395.

Sanford, H. N. (1948). In Grulee and Eley, ' The Child in Health and Disease', p. 470. Baltimore.

Schiff, E. (1938). Archives of Disease in Childhood, 13, 264.

Still, G. F. (1924). ' Common Disorders and Diseases of Childhood,' 4th ed., p. 336. London.

Thompson, W. P. (1939). Bull. N.Y. Acad. Med., 15, 177.

Whitby, L. E. H., Newns, G. H. (1949). In Garrod, Batten and Thursfield, 'Diseases of Children,' 4th ed., vol. 2, p. 727 . London.

Wintrobe, M. M. (1942). 'Clinical Hematology,' p. 389. London.

Vaughan, J. M. (1936). 'The Anaemias,' 2nd ed., p. 229. London. 